\title{
Simulation of turbulent non-premixed and partially premixed flames using a look-up table
}

\author{
Kazui FUKUMOTO* and Yoshifumi OGAMI* \\ * Department of Mechanical Engineering and Science, Ritsumeikan University, \\ 1-1-1 Nojihigashi, Kusatsu, Shiga, 525-8577, Japan \\ E-mail: fukumoto@cfd.ritsumei.ac.jp
}

Received 25 September 2013

\begin{abstract}
In this paper, we present a simple combustion simulation technique based on a look-up table approach. In the proposed technique, a flow solver extracts the solutions of the ordinary differential equations (ODEs) of the chemical equations from the look-up table using the mixture fraction, mass fraction of products, and time scale of the reaction. The look-up table is constructed during combustion simulation. Thus, prior calculation is not needed in the proposed technique. The solutions of the ODEs are saved in the look-up table at points where the mixture fraction, mass fraction, and time scale are similar to those in the look-up table. Once the data are recorded, a direct integration to solve the chemical equations becomes unnecessary, and the time required to compute the reaction rates is shortened. The proposed technique is applied to an eddy dissipation concept (EDC) model and is validated through a simulation of a $\mathrm{H}_{2}$ turbulent non-premixed flame and a $\mathrm{CH}_{4}$ partially premixed flame. The results obtained through the proposed technique are then compared with experimental data and computational data obtained using the EDC model with direct integration. We found a good agreement between our method and the EDC model. Moreover, although the proposed technique is simple, the computation time for our technique is faster than the in situ tabulation method (ISAT) and is approximately $99 \%$ lower than that of the EDC model with direct integration.
\end{abstract}

Key words : Turbulent non-premixed flame, Turbulent partially premixed flame, Eddy dissipation concept model, Tabulated chemistry, Look-up table, Jet flow, Turbulence, Computational fluid dynamics, Chemical reaction

\section{Introduction}

Because of the rapidly increasing availability of computing technologies, numerical simulations of turbulent combustion have become one of the major methods to predict fundamental phenomena of turbulence, combustion, and their interactions. Many unsteady combustion simulations have been performed to study these phenomena (Sadiki, et al., 2006, Godel, et al., 2009, Moureau, et al., 2011). However, the unsteady simulations require a high computational cost compared with steady simulations. Furthermore, the simulations of turbulent combustion that includes detailed chemical mechanisms also requires the high computational cost because a reaction calculation involves $\mathrm{n}$-dimensional ordinary differential equations (ODEs) that must be solved according to the number of chemical species.

Several techniques have been developed to overcome this problem. For example, the in-situ adaptive tabulation (ISAT) (Pope, 1997, Yang and Pope, 1998, Singer and Pope, 2006) method is based on in-situ generation of a look-up table constructed by solving for the time evolution of species concentrations directly, and it overcomes many of the difficulties associated with pre-computed look-up tables. This method has been adopted in ANSYS FLUENT using the eddy dissipation concept (EDC) model (Magnussen, 1981, Magnussen, 1989, Gran and Magnussen, 1995a, 1995b, Magnussen, 2005) and the probability density function (PDF) model (Bilger, 1980, Fox, 2003). The method of intrinsic low-dimensional manifolds (ILDM) (Maas and Pope, 1992, Maas and Pope, 1994, Gicquel, et al., 2000) allows the automatic reduction of detailed chemical mechanisms. This method is based on a direct mathematical analysis of the dynamic response behavior of non-linear chemical equations. A filtered, tabulated chemistry model for large eddy simulation (LES) was developed by Fiorina et al. (2010). This model can be applied to a premixed flame with the aim of recovering the correct laminar flame propagation speed of the filtered flame front. A laminar flamelet model (Peters, 
1984, Oijen, et al., 2001) is widely used for combustion simulation. Although this is a numerical model for computing the mass fraction of the chemical species in turbulent combustion, the computation time for performing a simulation using the flamelet model is very small. This is because, in this model, the temperature and mass fractions of chemical species are obtained from a look-up table that is constructed before the combustion simulation. The flamelet model is often applied to the unsteady simulation using the LES (Pierce and Moin, 2004, Carbonell, et al., 2009) or direct numerical simulation (DNS) (Ihme, et al., 2005, Baba and Kurose, 2008, Moriai, et al., 2013) because of its low computational cost.

To reduce the computation time, a combustion simulation technique based on a combination of the chemical equilibrium method and EDC model was developed in a previous study. The technique was validated by simulating a $\mathrm{H}_{2}$-air turbulent non-premixed flame (Fukumoto and Ogami, 2010), $\mathrm{CO}-\mathrm{H}_{2}$-air turbulent non-premixed flame (Fukumoto and Ogami, 2012), and $\mathrm{CH}_{4}$-air partial turbulent non-premixed flame (Ogami and Fukumoto, 2010). An advantage of the aforementioned technique is the ease with which a reduced chemical mechanism can be modeled according to the accuracy requirements of the chemical species. Thus, the technique can predict intermediate species with high accuracy when a reduced mechanism is modeled for the minor species. In this technique, a lower number of species were modified by the chemical equations, resulting in lower computational time. However, the prediction accuracy also depends on the number of modified species.

In this work, we present a simple simulation technique based on the look-up table. This technique has been developed to quickly obtain the solutions of ODEs of the chemical equations. In the proposed technique, the reaction rates are computed from the look-up table data, if available. However, if the data are not available, the reaction equation is directly integrated and the obtained data are stored in the look-up table according to the look-up table indexes. Once the solutions of the ODEs are recorded in the look-up table, further direct integration of the chemical equations becomes unnecessary, and the computation time can be shortened while retaining high accuracy.

The primary advantage of our technique is that it is easy to build the program because of its simple algorithm. Secondly, it is not necessary to construct the look-up table prior to the combustion simulation, because the look-up table is constructed during the combustion simulation itself. Thirdly, this technique can be easily applied to combustion models if the proper variables are chosen for the look-up table indexes. Fourthly, the proposed technique is applicable under various conditions such as a non-premixed or partially premixed flame if the phenomena are organized according to the indexes.

The proposed technique was tested by simulating a $\mathrm{CO}-\mathrm{H}_{2}$ turbulent non-premixed flame (Fukumoto and Ogami, 2012a) and a $\mathrm{CH}_{4}-\mathrm{H}_{2}$ turbulent non-premixed flame (Fukumoto and Ogami, 2012b) in the previous study. In this paper, the proposed technique was applied to the EDC model and validated by computing a $\mathrm{H}_{2}$ turbulent non-premixed flame (Takagi and Kotoh, 1982) and a $\mathrm{CH}_{4}$ turbulent partially premixed flame (TNF Workshop); the results were compared with the experimental data, and the computation time for the proposed technique was discussed.

\section{Method}

\subsection{Overview of the simulation}

ANSYS FLUENT 14.5 was used in this study. The momentum equation, turbulence model, and mass fraction equation were computed using ANSYS FLUENT. To solve the momentum equation, the velocity and pressure were coupled using the semi implicit method for pressure linked equations (SIMPLE) (Patankar, 1985), and the basic Reynolds stress model in ANSYS FLUENT (Ansys, Inc, 2010) was chosen as the turbulence model. The time-averaged reaction rates of each chemical species were calculated using a user-defined function (UDF). The UDF is a function that can be programmed to load the solver dynamically to enhance the standard features of ANSYS FLUENT. The look-up table was employed to quickly obtain the solutions of the ODEs of the reaction equations. The simplified transport model proposed by Smooke (1991) was programmed as the UDF to compute the viscosity, thermal conductivity, and mass diffusivity.

\subsection{Theory of the EDC model}

In this study, the EDC model (Gran and Magnussen, 1995b) was used as the combustion model. An overview of the EDC model is illustrated in Fig. 1. In the EDC model, it is assumed that combustion occurs in the fine structure of 
the turbulent flow. The fine structure is considered a perfectly stirred reactor (PSR) as

$$
\begin{aligned}
& \frac{d Y_{J}^{*}}{d t}=\frac{w_{J}^{*}}{\bar{\rho}}+\frac{Y_{J}^{0}-Y_{J}^{*}}{\tau^{*}} \text { and } \\
& \tilde{Y}_{J}=\xi^{* 3} Y_{J}^{*}+\left(1.0-\xi^{* 3}\right) Y_{J}^{0},
\end{aligned}
$$

where $\tilde{Y}_{J}$ is the mass fraction of chemical species $J$, and $Y_{J}^{*}$ and $Y_{J}^{0}$ are the mass fractions of chemical species $J$ in the fine structure and surrounding gas, respectively. Time is denoted by $t, w_{J}^{*}$ is the reaction rate of chemical species $J$ in the fine structure, $\bar{\rho}$ is the density, $\tau^{*}$ is the time scale of the reaction, and $\xi^{*}$ is the length of the fine structure. The tilde and overbar represent the density-weighted and time average, respectively. Substituting $Y_{J}^{0}$ in Equation (1) with that in Equation (2) gives

$$
\frac{d Y_{J}^{*}}{d t}=\frac{w_{J}^{*}}{\bar{\rho}}+\frac{\tilde{Y}_{J}-Y_{J}^{*}}{\left(1-\xi^{* 3}\right) \tau^{*}} .
$$

The above ODEs are solved at steady state under the initial conditions obtained from the current mass fractions, density, and temperature in each computational cell. $\xi^{*}$ is computed as

$$
\xi^{*}=C_{\xi}\left(\frac{\mu \epsilon}{\bar{\rho} k^{2}}\right)^{\frac{1}{4}}
$$

where $C_{\xi}=2.1377, \mu$ denotes the viscosity, $\epsilon$ is the turbulent dissipation rate, and $k$ denotes the turbulent kinetic energy. $\tau^{*}$ is given by

$$
\tau^{*}=C_{\tau}\left(\frac{\mu}{\bar{\rho} \epsilon}\right)^{\frac{1}{2}},
$$

where $C_{\tau}=0.408$. The time-averaged reaction rate $\bar{w}_{J}$ of chemical species $J$ is computed as

$$
\bar{w}_{J}=\frac{\bar{\rho} \xi^{* 2}}{\left(1-\xi^{* 3}\right)} \frac{\left(Y_{J}^{*}-\tilde{Y}_{J}\right)}{\tau},
$$

where $\left(Y_{J}^{*}-\tilde{Y}_{J}\right) / \tau$ is replaced by the data in the look-up table.

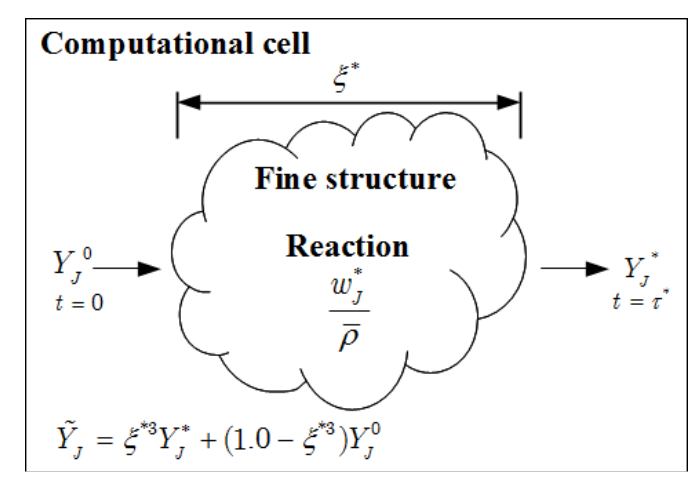

Fig. 1 Overview of the EDC model 


\subsection{Construction of the look-up table}

A look-up table was used to reduce the computation time. The proposed technique was applied to the EDC model in this study. The EDC model was chosen in this study because this model requires the reaction calculation, and it is easy to build the program. However, our technique could be easily applied to various reactive flows if the proper variables were chosen for the indexes of the look-up table.

Figure 2 shows the algorithm of the proposed technique. In the proposed technique, the reaction rates are obtained from the look-up table if data are available. However, if the data are not available in the look-up table, the ODEs of the reaction equation are solved, and the obtained results are stored in the look-up table according to the indexes. In this study, the mixture fraction, mass fraction of products, and time scale of the reaction were chosen as the indexes because turbulent non-premixed and partially premixed flames are mainly dependent upon by these variables. The mass fraction of products was defined as either the mass fraction of $\mathrm{H}_{2} \mathrm{O}$ or the sum of the mass fractions of $\mathrm{CO}_{2}$ and $\mathrm{CO}$. The time scale was calculated in the EDC model. The computation time was reduced with an increase in the amount of reaction rate data in the look-up table, as solving the ODEs became unnecessary.

Figure 3 shows a schematic of the look-up table construction. For simplicity, only a two-dimensional look-up table is illustrated in Fig. 3. If the look-up table data are not available at the stored points $\mathrm{Q}_{\mathrm{n}, \mathrm{m}}, \mathrm{Q}_{\mathrm{n}+1, \mathrm{~m}}, \mathrm{Q}_{\mathrm{n}, \mathrm{m}+1}$, or $\mathrm{Q}_{\mathrm{n}+1, \mathrm{~m}+1}, \quad Y^{*}$ is computed using the EDC model because the linear interpolation cannot be performed without these neighbor points. Then the change in the mass fraction per unit time $W_{P}$ is given as

$$
W_{P}=\frac{Y^{*}-\tilde{Y}}{\tau^{*}}
$$

where $\tilde{Y}$ is the mass fraction of a chemical species and $Y^{*}$ denotes the mass fraction of the chemical species in the fine structure.
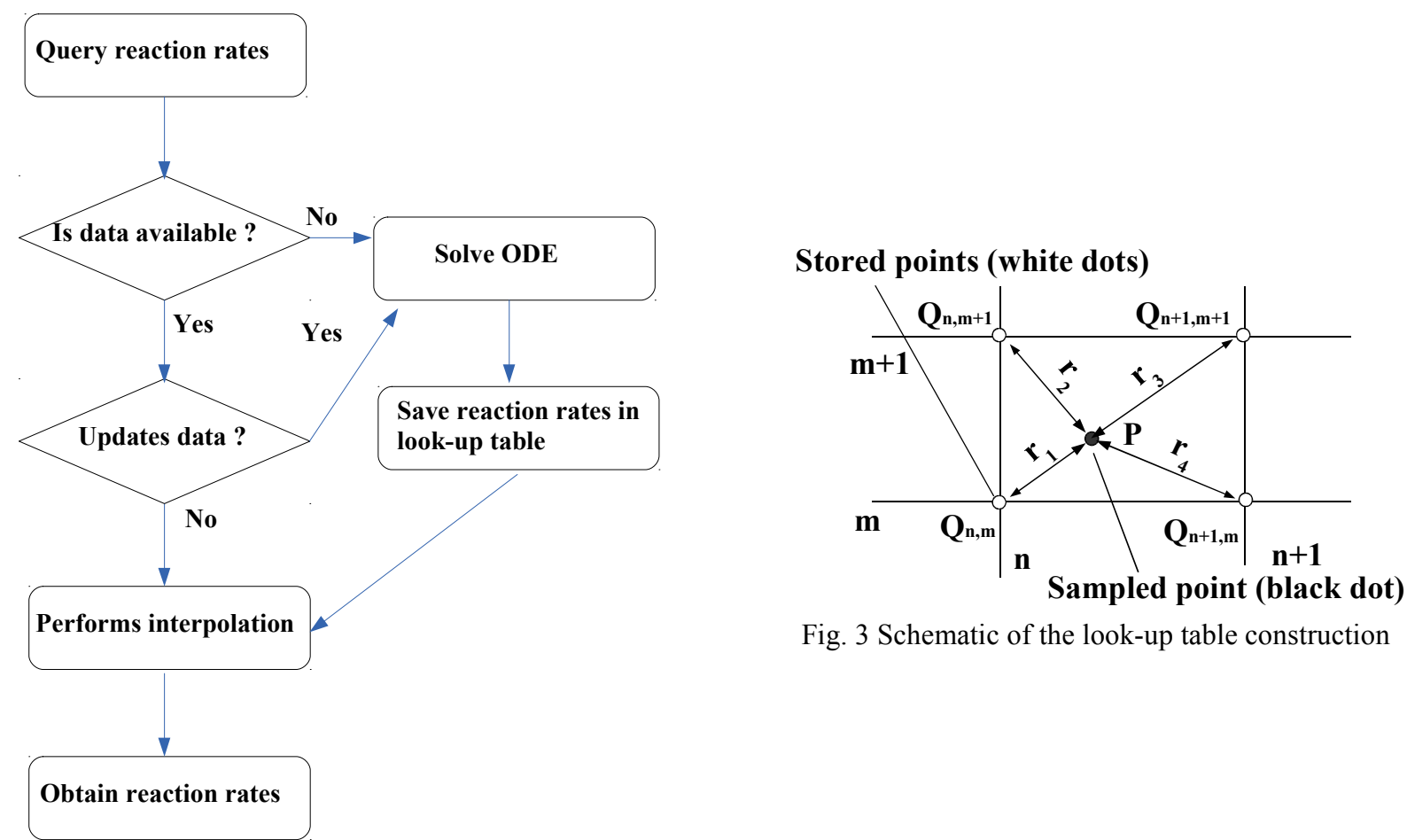

Fig. 3 Schematic of the look-up table construction

Fig. 2 Algorithm of our technique 
$W_{p}$ is weighted according to the normalized distance $\mathbf{r}$ between sampled point $\mathrm{P}$ and stored points $\mathrm{Q}$. Furthermore, the data in the same index are averaged by the sum of the weight function. Finally, the $L$ th saving data $W_{Q, L}$ in the look-up table is computed as

$$
W_{Q, L}=\frac{g W_{Q, L-1}+f_{L} W_{P}}{g+f_{L}},
$$

where $W_{Q, L}$ is saved at the stored points $\mathrm{Q}_{\mathrm{n}, \mathrm{m}}, \mathrm{Q}_{\mathrm{n}+1, \mathrm{~m}} \mathrm{Q}_{\mathrm{n}, \mathrm{m}+1}$, and $\mathrm{Q}_{\mathrm{n}+1, \mathrm{~m}+1}, L$ is the number of writing data, $f_{L}$ is the $L$ th weight function, and $g$ is the sum of the weight function. $W_{P}$ is obtained at the sampled point $\mathrm{P}$, and there is a distance between the sampled point $\mathrm{P}$ and stored points $\mathrm{Q}$. The weight function and sum of the weight function are computed as

$$
\begin{aligned}
& f_{l}=\exp \left(-\frac{\mathbf{r}}{0.2 \sqrt{N}}\right) \text { and } \\
& g=\min \left(\sum_{l}^{L-1} f_{l}, 5.0\right),
\end{aligned}
$$

where $f_{l}$ and $g$ denote the $l$ th weight function and sum of the weight function, respectively. $\mathbf{r}$ is ranging from 0 to $\sqrt{N}, N$ is the number of indexes, and $g$ determines the effect of $W_{Q, L-1}$. However, if data are missing at the stored point, $f_{l}$ is set to 1 .

The linearly interpolated data $W_{\text {interp }}$ is computed using the stored points $\mathrm{Q}_{\mathrm{n}, \mathrm{m}}, \mathrm{Q}_{\mathrm{n}+1, \mathrm{~m}} \mathrm{Q}_{\mathrm{n}, \mathrm{m}+1}$, and $\mathrm{Q}_{\mathrm{n}+1, \mathrm{~m}+1}$, if the index variables are inside the stored points $\mathrm{Q}_{\mathrm{n}, \mathrm{m}}, \mathrm{Q}_{\mathrm{n}+1, \mathrm{~m}} \mathrm{Q}_{\mathrm{n}, \mathrm{m}+1}$, and $\mathrm{Q}_{\mathrm{n}+1, \mathrm{~m}+1}$. The time-averaged reaction rate $\bar{w}$ is calculated as

$$
\bar{w}=\frac{\bar{\rho} \xi^{* 2}}{\left(1-\xi^{* 3}\right)} W_{\text {interp }}
$$

The stored data are randomly updated, and the probability of an update is set to $1 / 1000$ as a default value. This parameter determines the theoretical maximum speed of the proposed technique. The random update is used to improve the data in the look-up table because the table is constructed using a few indexes. Thus, the influence of eliminated variables such as minor species is not directly taken into account, while the random update gradually enables these effects to be considered in the look-up table.

The mixture fraction $\tilde{Z}$, which is the one of the look-up table indexes, is computed as

$$
\frac{\partial\left(\bar{\rho} \tilde{u}_{j} \tilde{Z}\right)}{\partial x_{j}}=\frac{\partial}{\partial x_{j}}\left(\frac{\mu_{t}}{\sigma_{m}} \frac{\partial \tilde{Z}}{\partial x_{i}}\right),
$$

where $\tilde{u}_{j}$ is the velocity in direction $j, x_{j}$ is the coordinate of direction $j, \mu_{t}$ is the turbulent viscosity, and $\sigma_{m}$ is the effective Schmidt number.

\subsection{Numerical conditions}

Two types of turbulent flames were calculated to verify the accuracy of the proposed technique. In the case of the $\mathrm{H}_{2}$-air turbulent non-premixed flame, the numerical conditions were based on Takagi's experiment (Takagi and Kotoh, 1982). Figure 4 shows a sketch of the computational domain used in this study. The mass fractions of $\mathrm{H}_{2}$ and $\mathrm{N}_{2}$ in the fuel were $4.7 \mathrm{e}-2$ and 9.53e-1, respectively. In ambient air, the mass fractions of $\mathrm{O}_{2}$ and $\mathrm{N}_{2}$ were $2.33 \mathrm{e}-1$ and $7.67 \mathrm{e}-1$, respectively. The velocities of the fuel, co-flow, and weak flow were 55.7, 5.1, and $0.051 \mathrm{~m} / \mathrm{s}$, respectively. The no-slip condition was adopted as the boundary condition of the wall. The atmosphere velocity indicated in Fig. 4 was 0.051 
$\mathrm{m} / \mathrm{s}$ in the axial direction. The temperatures of the fuel, co-flow, weak flow, and atmosphere were considered to be $300.0 \mathrm{~K}$. A second-order upwind difference was applied to the governing equations of the momentum, mass fraction of chemical species $J$, mixture fraction, and energy. The 2D axisymmetric solver in ANSYS FLUENT was chosen using the axis indicated by the centerline of Fig. 4. The Reynolds stress model was chosen as the turbulence model; the model parameters ( $C_{2 \epsilon}=1.79$, the effective Prandtl number $\sigma_{h}=0.6$, and the Schmidt number $\sigma_{m}=0.6$ ) were set to adjust the axial velocity profile of the experimental data. In this study, the detailed chemical mechanism of the $\mathrm{H}_{2}$ reaction suggested by Barlow and Smith (1999) was used to compute the reaction rates. This mechanism involves 9 species, and $\mathrm{H}_{2} \mathrm{O}$ was chosen as the product species for the look-up table.

The numerical conditions of the $\mathrm{CH}_{4}$-air turbulent partially premixed flame were based on Sandia flame D (TNF Workshop). Figure 5 shows a sketch of the computational domain used in this study. The mass fractions of $\mathrm{CH}_{4}, \mathrm{O}_{2}$, and $\mathrm{N}_{2}$ in the fuel were 1.56e-1, 1.97e-1, and 6.47e-1, respectively. In the pilot flame, the mass fractions of $\mathrm{N}_{2}, \mathrm{O}_{2}, \mathrm{O}_{\text {, }}$ $\mathrm{H}_{2}, \mathrm{H}, \mathrm{H}_{2} \mathrm{O}, \mathrm{CO}, \mathrm{CO}_{2}$, and $\mathrm{OH}$ were $7.34 \mathrm{e}-1,5.40 \mathrm{e}-2,7.47 \mathrm{e}-4,1.29 \mathrm{e}-4,2.48 \mathrm{e}-5,9.42 \mathrm{e}-2,4.07 \mathrm{e}-3,1.10 \mathrm{e}-1$, and $2.8 \mathrm{e}-3$, respectively. The mass fractions of $\mathrm{O}_{2}$ and $\mathrm{N}_{2}$ in the co-flow were $2.33 \mathrm{e}-1$ and $7.67 \mathrm{e}-1$, respectively. The velocities of the fuel, pilot flame, and co-flow were $49.6 \mathrm{~m} / \mathrm{s}, 11.4 \mathrm{~m} / \mathrm{s}$, and $0.9 \mathrm{~m} / \mathrm{s}$. The atmosphere velocity indicated in Fig. 5 was $0.9 \mathrm{~m} / \mathrm{s}$ in the axial direction. The no-slip condition was applied to the walls. The temperatures of the fuel, pilot flame, co-flow, and atmosphere were $294 \mathrm{~K}, 1880 \mathrm{~K}, 291 \mathrm{~K}$, and $291 \mathrm{~K}$, respectively. A second-order upwind difference was applied to the governing equations of the momentum, mass fraction of chemical species $J$, mixture fraction, and energy. The 2D axisymmetric solver in ANSYS FLUENT was chosen using the axis indicated by the centerline of Fig. 5. The Reynolds stress model was chosen as the turbulence model; the model parameters $\left(C_{2 \epsilon}=1.75\right.$, effective Prandtl number $\sigma_{h}=0.6$, and Schmidt number $\left.\sigma_{m}=0.6\right)$ were set to adjust the axial velocity profile of the experimental data. In this study, GRI-Mech 2.11 (Bowman, et al.), including 49 species, and the mechanism suggested by Kee et al. (1985), containing 17 species, were used to calculate the reaction rates, and $\mathrm{CO}$ and $\mathrm{CO}_{2}$ were chosen as the product species for the look-up table.

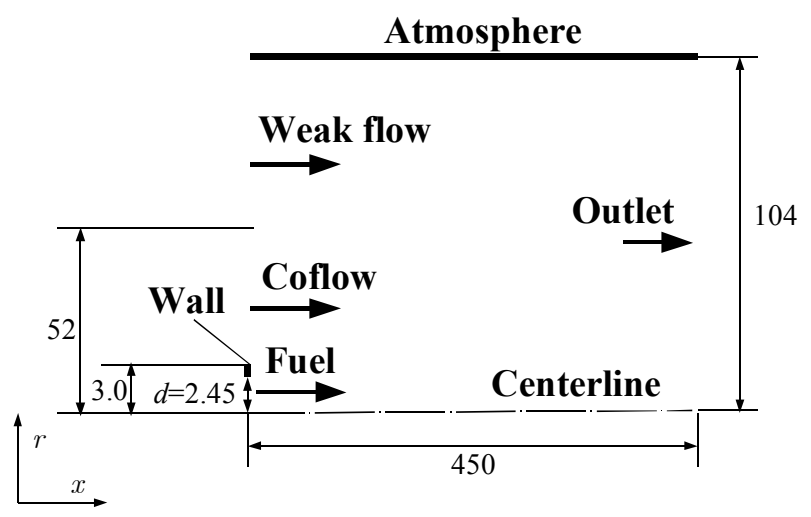

Fig. 4 Sketch of the computational domain of the $\mathrm{H}_{2}$-air non-premixed flame. (Unit [mm])

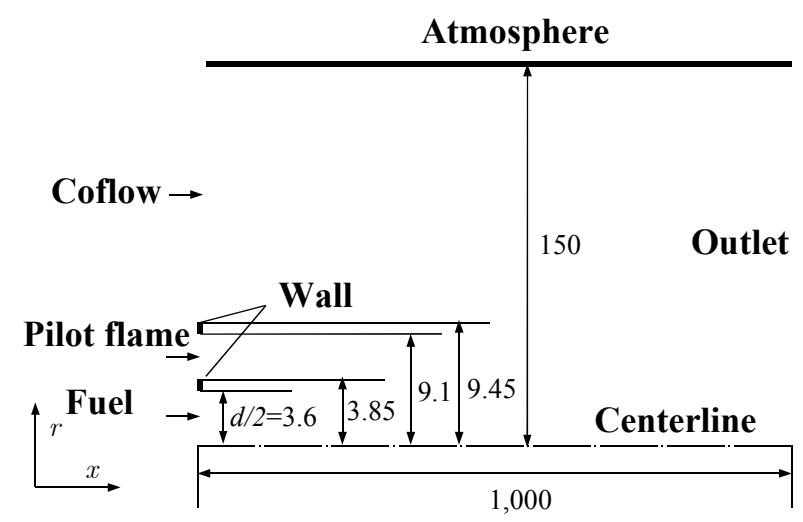

Fig. 5 Sketch of the computational domain of the $\mathrm{CH}_{4}$-air partially premixed flame. (Unit [mm])

\section{Results}

\subsection{Comparison with experimental data}

First, we verified the influence of the total number of computational cells on the numerical error, as this error must be minimized to increase the prediction accuracy of the proposed technique. Two different grids were prepared to examine the influence of the number of cells. The chosen indexes of the look-up table were the mixture fraction, sum of 
the mass fractions of the product species, and time scale of the reaction; each coordinate of the look-up table was divided into $200 \times 200 \times 200$ cells. Barlow's mechanism and GRI-Mech 2.11 were employed for the $\mathrm{H}_{2}$ and $\mathrm{CH}_{4}$ reactions, respectively. Figures 6 and 7 show plots of the mole and mass fractions and temperatures predicted using the two different grids. The results were similar for the two grids, and the difference was negligible. Grids with 67,000 and 53,000 cells were chosen for the simulations discussed in the following sections.

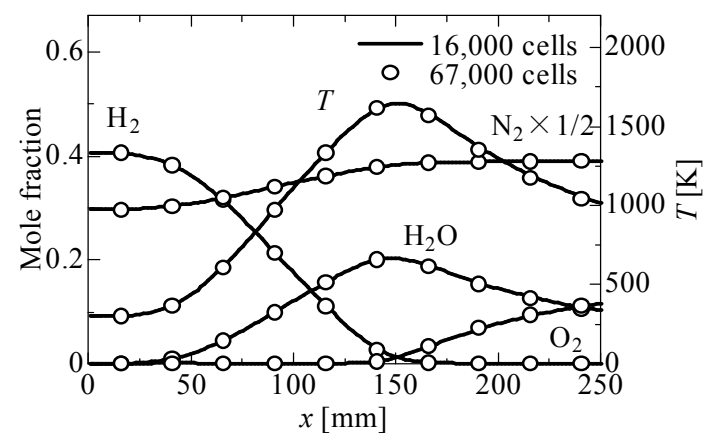

Fig. 6 Axial profiles of mole fractions and temperature of the $\mathrm{H}_{2}$-air non-premixed flame predicted using different grids

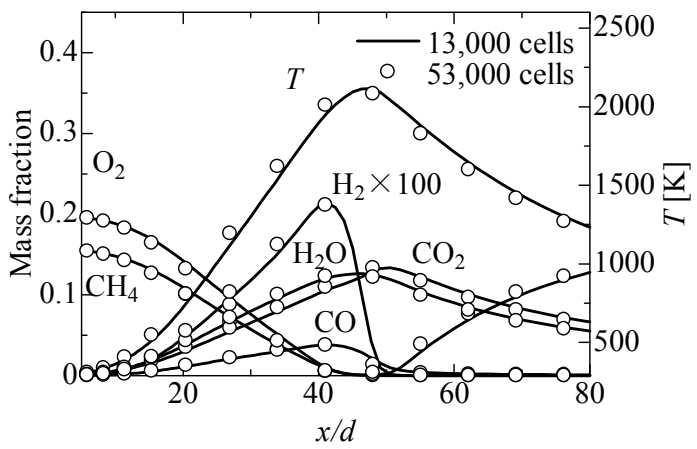

Fig. 7 Axial profiles of mass fractions and temperature of the $\mathrm{CH}_{4}$-air partially premixed flame predicted using different grids

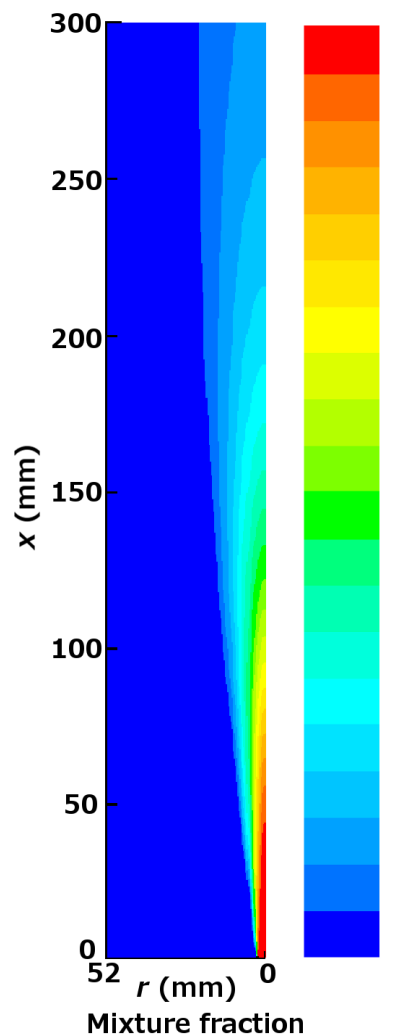

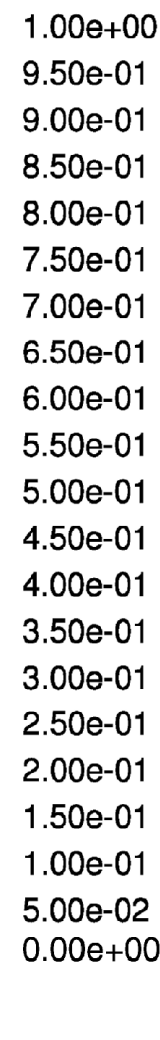

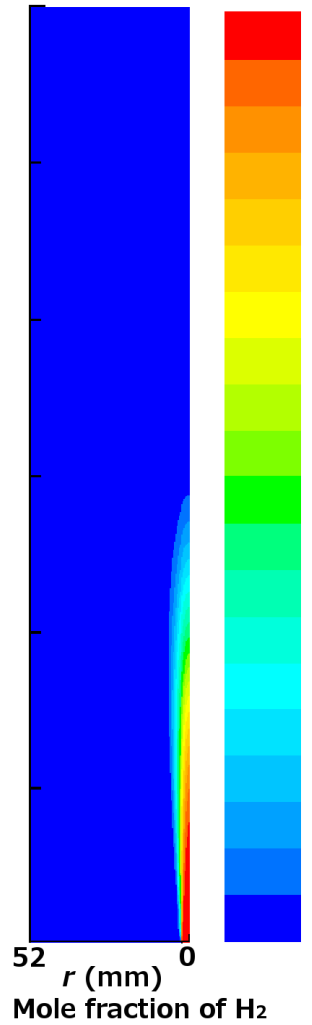

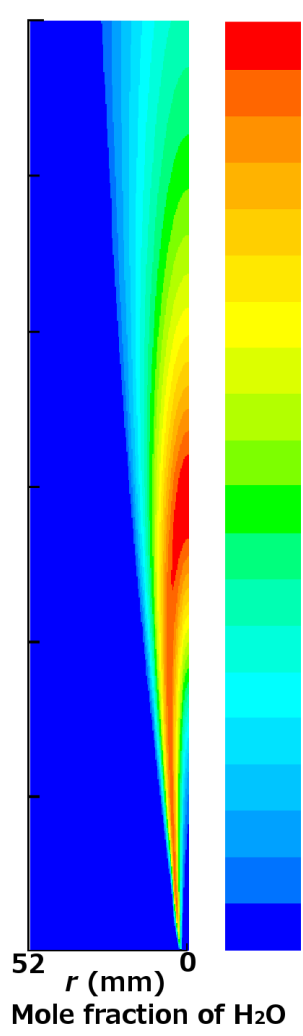

$2.03 e-01$

$1.92 \mathrm{e}-01$

$1.82 \mathrm{e}-01$

$1.72 \mathrm{e}-01$

$1.62 \mathrm{e}-01$

$1.52 \mathrm{e}-01$

$1.42 \mathrm{e}-01$

$1.32 \mathrm{e}-01$

$1.22 \mathrm{e}-01$

$1.11 \mathrm{e}-01$

$1.01 \mathrm{e}-01$

9.12e-02

8.10e-02

$7.09 \mathrm{e}-02$

$6.08 \mathrm{e}-02$

$5.07 \mathrm{e}-02$

$4.05 \mathrm{e}-02$

$3.04 \mathrm{e}-02$

$2.03 \mathrm{e}-02$

$1.01 \mathrm{e}-02$

$0.00 \mathrm{e}+00$

Fig. 8 Distributions of the mixture fraction, mole fractions, time scale and temperature of the $\mathrm{H}_{2}$-air non-premixed flame on $x$ - $r$ plane 

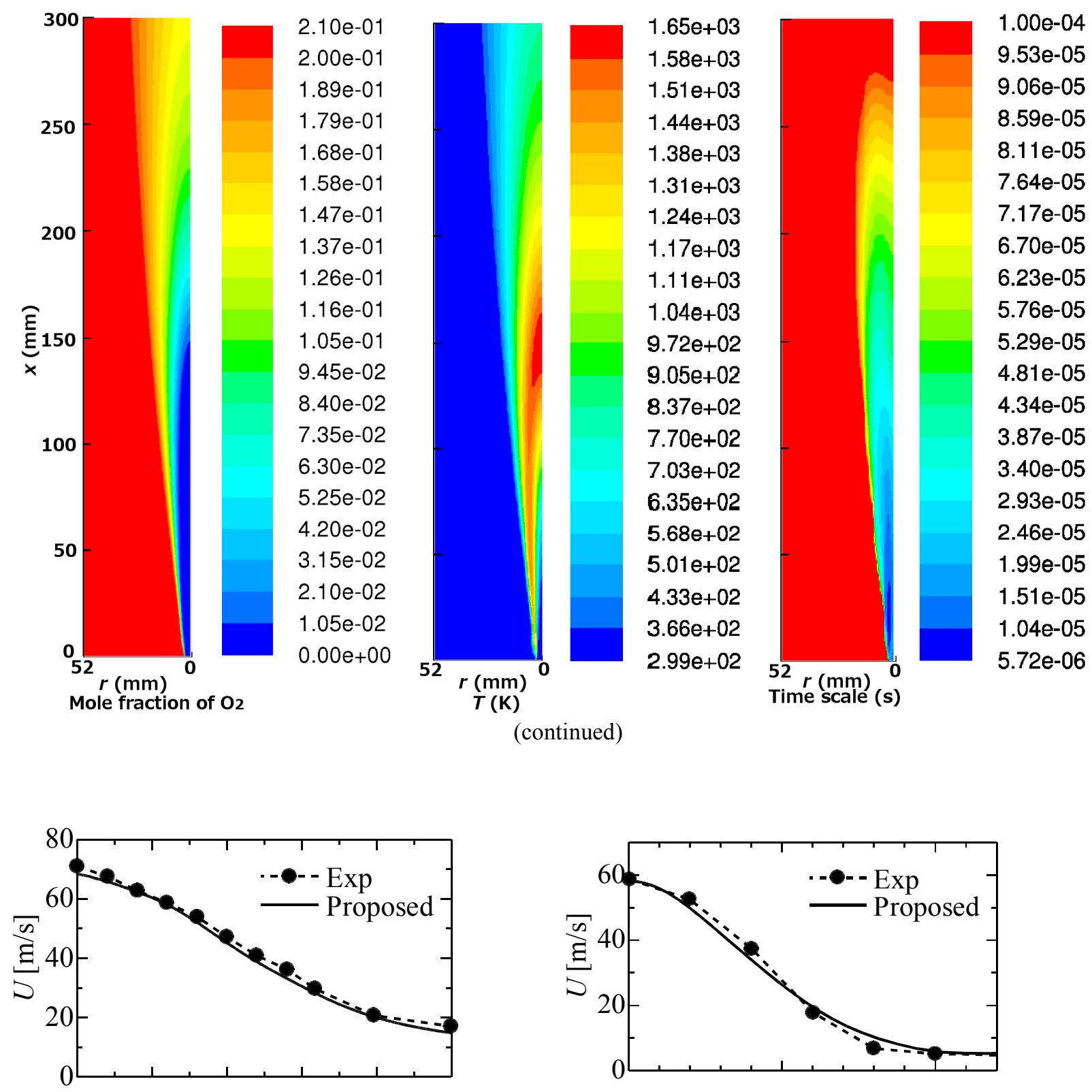

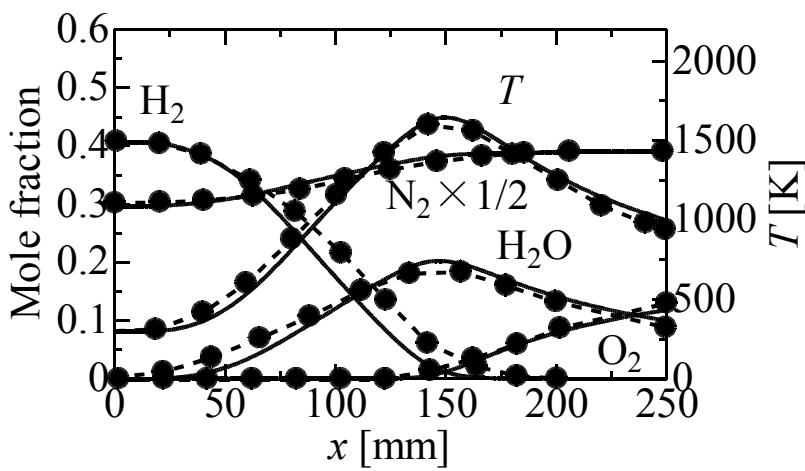

(a)

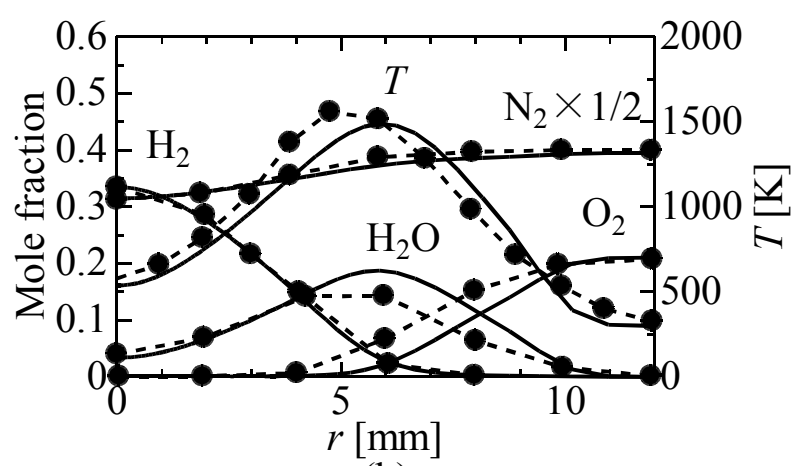

(b)

Fig. 9 (a) Axial profiles of velocity (top), mole fractions and temperature (bottom) at centerline, (b) radial profiles of velocity (top), mole fractions and temperature (bottom) at $x=60 \mathrm{~mm}$, and (c) radial profiles of velocity (top), mole fractions and temperature (bottom) at $x=160 \mathrm{~mm}$ of the $\mathrm{H}_{2}$-air non-premixed flame compared with experimental data. 

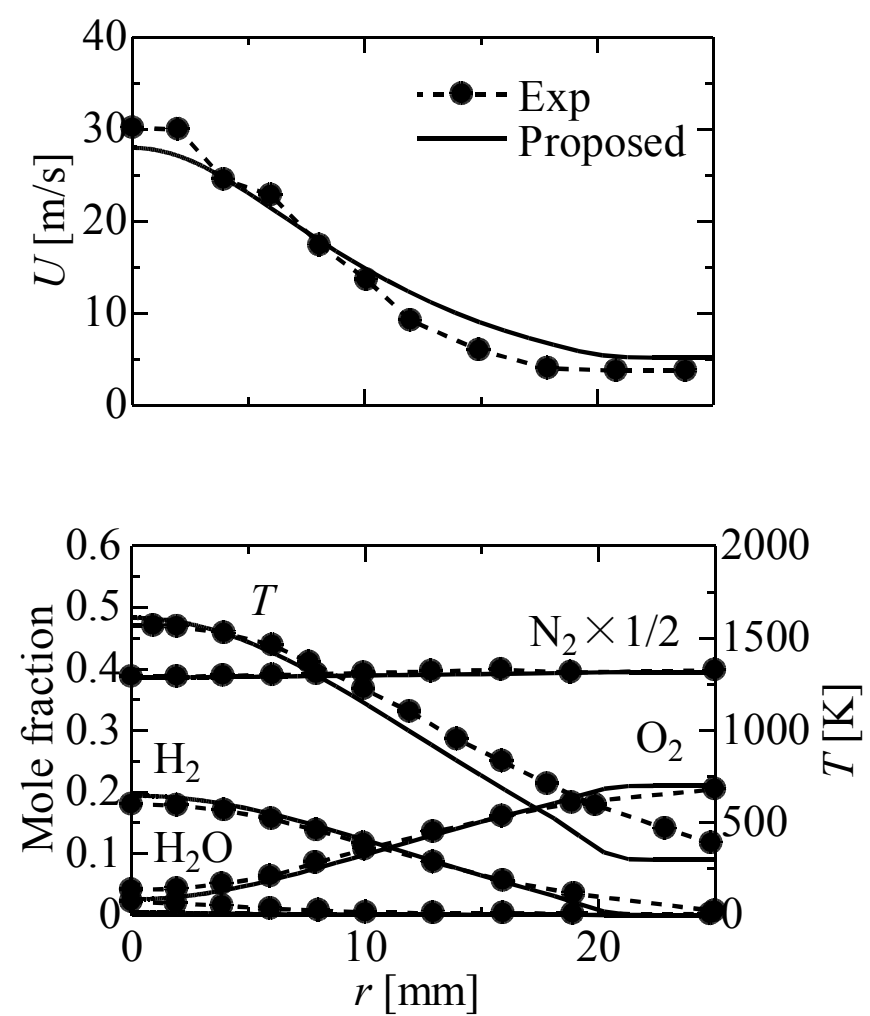

(c)

(continued)

Next, we compared the results obtained using our technique with the experimental data obtained by Takagi (1982) and Barlow (TNF Workshop). Figure 8 shows the distributions of the mixture fraction, mole fractions, temperature and time scale on $x-r$ plane. The distribution of the mole fraction of $\mathrm{H}_{2} \mathrm{O}$ was similar to that of the temperature. Increasing temperature was caused by the production of $\mathrm{H}_{2} \mathrm{O}$ in the non-premixed flame. The distribution of the time scale was the smallest near the nozzle. The time scale is determined based on $v, \rho$, and $\epsilon$ according to Equation (5). When the time scale is small, the chemical reaction is close to the state of non-equilibrium because the influence of the second term of the right hand in Equation (1) is considerable. Conversely, the chemical reaction approaches the state of equilibrium when the time scale is big. Thus, the state of non-equilibrium was observed near the nozzle in the non-premixed flame. However, the reaction rate of $\mathrm{H}_{2}$ is high, and the effect of the time scale was relatively small.

In Figures 9 and 11, "Exp" indicates the experimental data, and the look-up table size was set to $200 \times 200 \times 200$ cells. In Fig. 9 (a), the velocity obtained through the proposed technique was close to the experimental data. The parameter of the turbulence model $C_{2 \epsilon}$ was used to adjust the axial velocity. Generally, the turbulence model parameters changed according to the flow geometry of the combustion simulation (Zhou, et al., 2000). The peaks of the $\mathrm{H}_{2} \mathrm{O}$ mole fraction and temperature were slightly higher than those of the experiment because the $\mathrm{H}_{2}$ consumption was overestimated at $50 \mathrm{~mm}<x<200 \mathrm{~mm}$. In Fig. 9 (b), the radial velocity profile at $x=60 \mathrm{~mm}$ roughly agreed with the experimental data. The locations of the $\mathrm{H}_{2} \mathrm{O}$ mole fraction and temperature peaks were not close to those of the experimental data. In addition, the peak $\mathrm{H}_{2} \mathrm{O}$ mole fraction was higher than that of the experiment, and the $\mathrm{O}_{2}$ mole fraction at $5 \mathrm{~mm}<r$ was underestimated. As can be seen in Fig. 9 (c), the radial velocity profile was relatively high at $10 \mathrm{~mm}<r$. Compared with the experimental data at approximately $12 \mathrm{~mm}<r$ outside the flame, the $\mathrm{H}_{2}$ mole fraction was lower, $\mathrm{O}_{2}$ mole fraction was somewhat higher, and temperature was higher. We found that the mixing of the fuel and oxidant was slightly strong at $12 \mathrm{~mm}<r$. Although slight differences can be seen in Fig. 9, the results obtained 
through the proposed technique tended to deviate from the experimental data.

Figure 10 shows the distributions of the mixture fraction, mass fractions, temperature and time scale on $x$ - $r$ plane. The distributions of the mass fractions of $\mathrm{H}_{2} \mathrm{O}$ and $\mathrm{CO}_{2}$ were similar to the temperature distribution. Thus, the production of $\mathrm{H}_{2} \mathrm{O}$ and $\mathrm{CO}_{2}$ led to an increase in the temperature in the partially premixed flame. The distribution of the time scale of the partially premixed flame was similar to that of the non-premixed flame because the time scale in the EDC model was determined based on $v, \rho$, and $\epsilon$. These values are subject to the shape of the computational domain. The effect of the time scale can be seen from the mass fraction of $\mathrm{O}_{2}$ because $\mathrm{O}_{2}$ remained inside the flame.
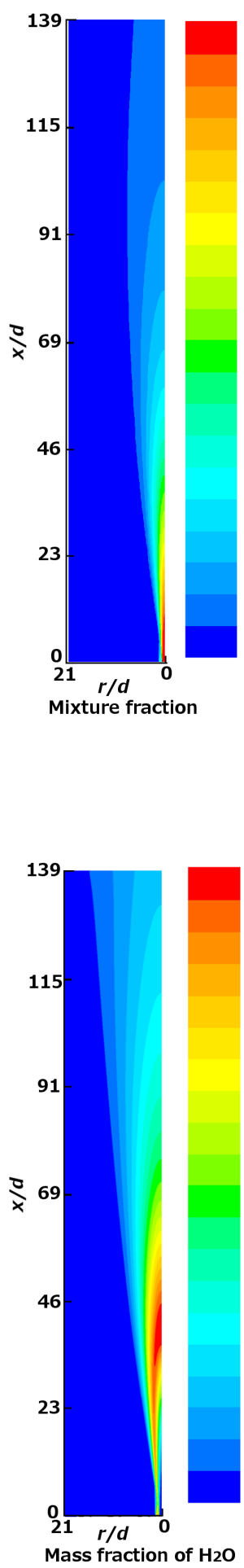
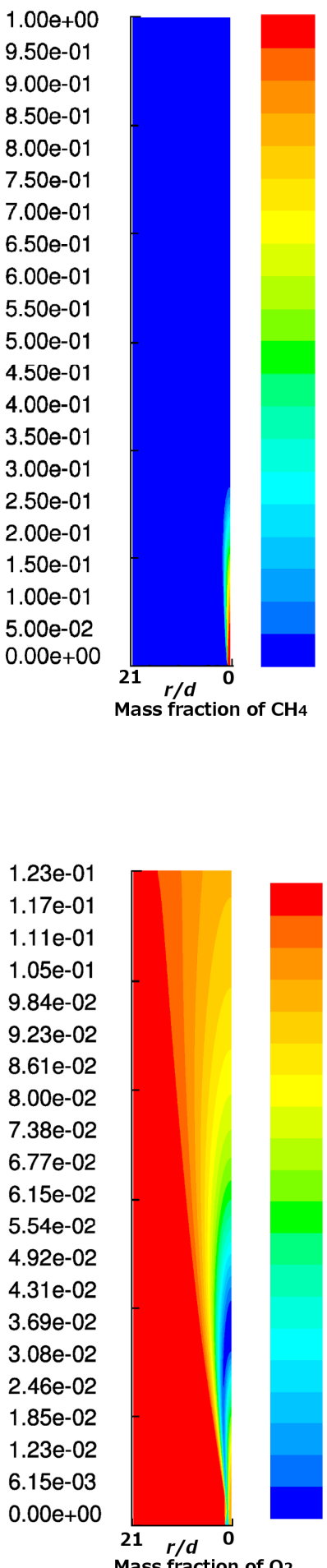

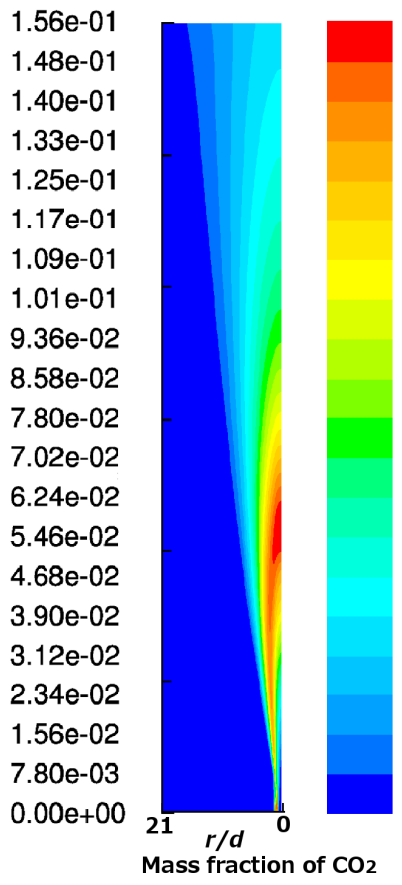

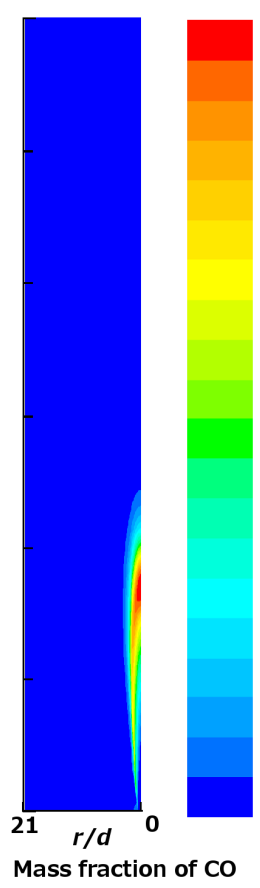

5.50e-02 5.23e-02 4.95e-02 4.68e-02 4.40e-02 4.13e- 02 3.85e- 02 3.58e-02 3.30e-02 3.03e-02 2.75e-02 2. $48 \mathrm{e}-02$ 2.20e-02

$1.93 \mathrm{e}-02$

$1.65 \mathrm{e}-02$

$1.38 \mathrm{e}-02$

$1.10 \mathrm{e}-02$ $8.25 \mathrm{e}-03$ $5.50 \mathrm{e}-03$ $2.75 \mathrm{e}-03$ $0.00 \mathrm{e}+00$
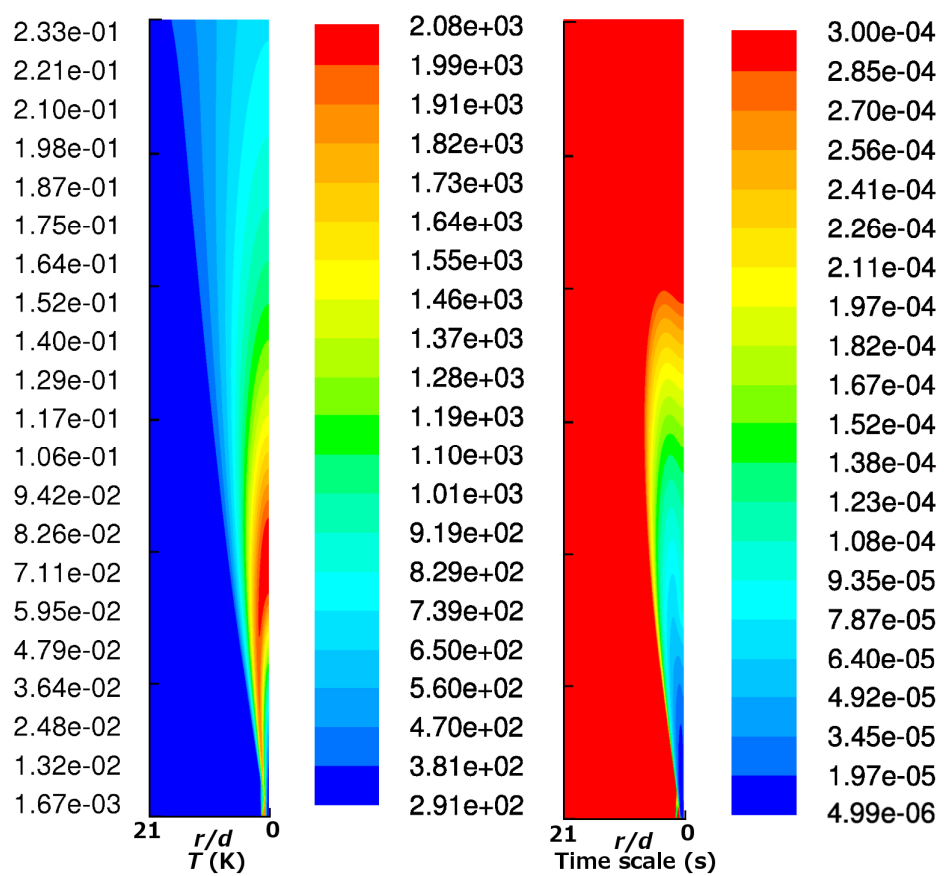

Fig. 10 Distributions of the mixture fraction, mass fractions, time scale and temperature of the $\mathrm{CH}_{4}$-air partially premixed flame on $x-r$ plane 

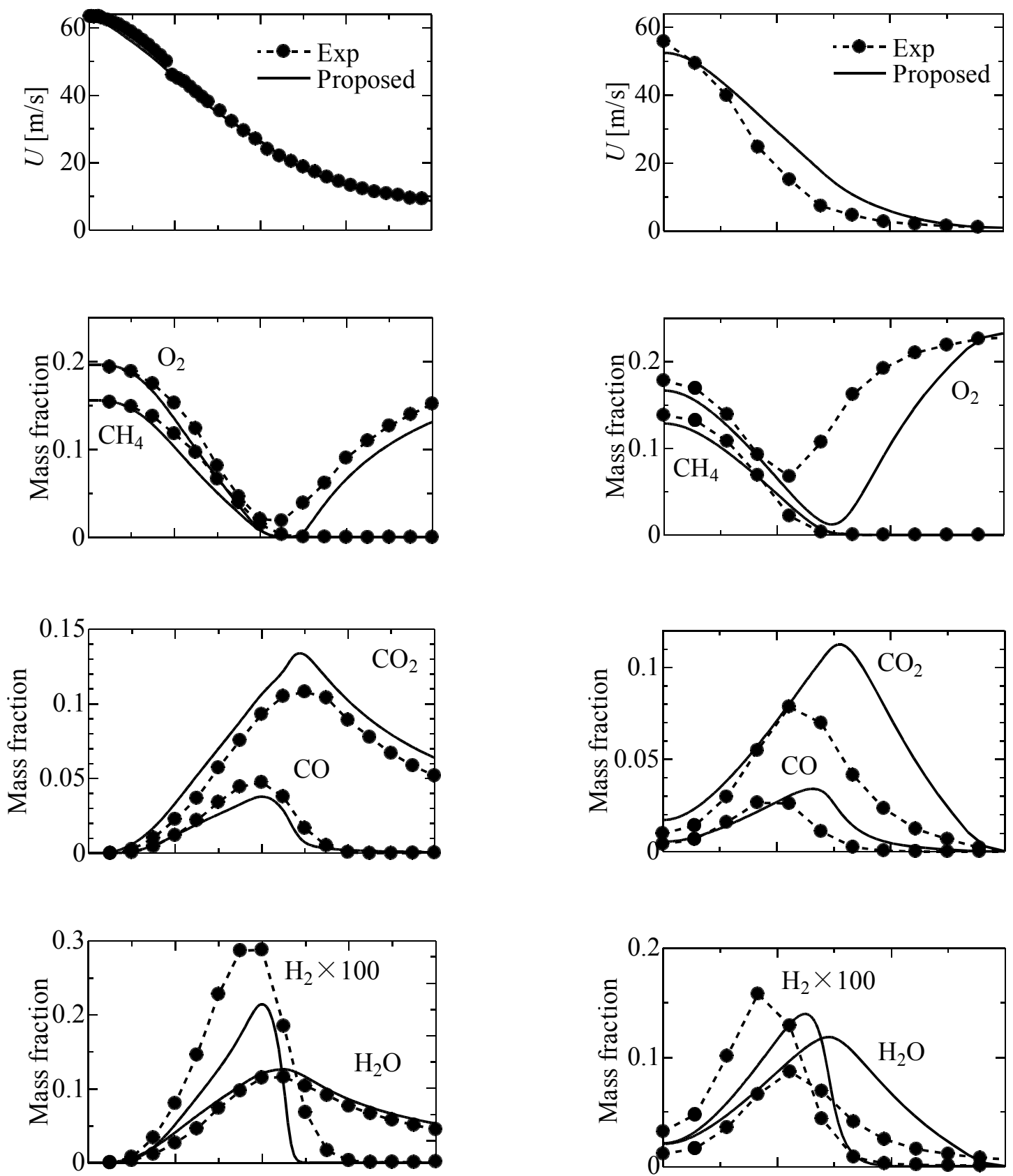

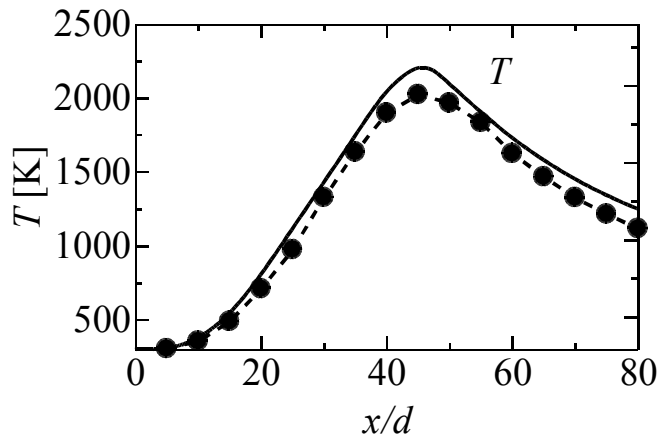

(a)

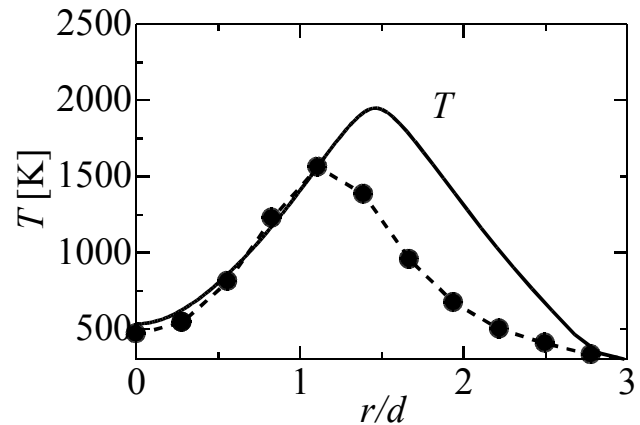

(b)

Fig. 11 (a) Axial profiles of velocity, mass fractions and temperature at centerline, (b) radial profiles of velocity, mass fractions and temperature at centerline $x / d=15$, (c) radial profiles of velocity, mass fractions and temperature at $x / d=30$, and

(d) radial profiles of velocity, mass fractions and temperature at $x / d=45$ of the $\mathrm{CH}_{4}$-air partially premixed flame compared with experimental data. 
Fukumoto and Ogami, Journal of Thermal Science and Technology, Vol.9, No.1 (2014)
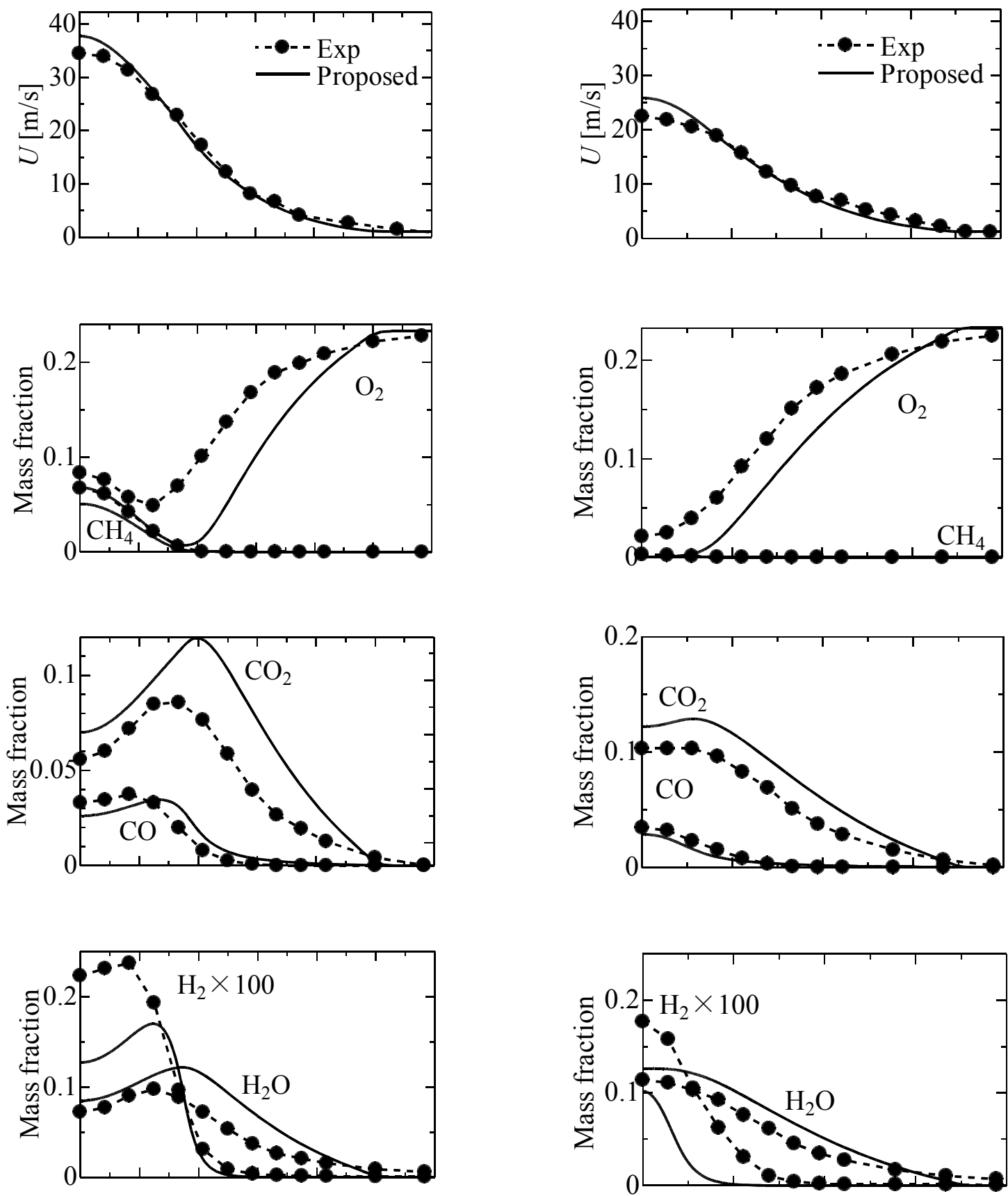

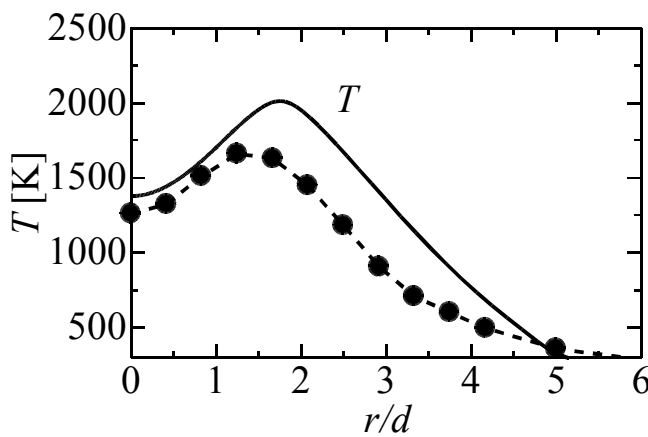

(c)

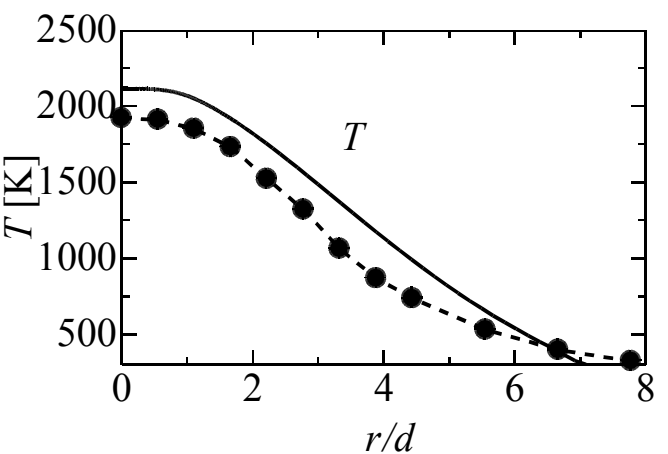

(d)

(continued) 


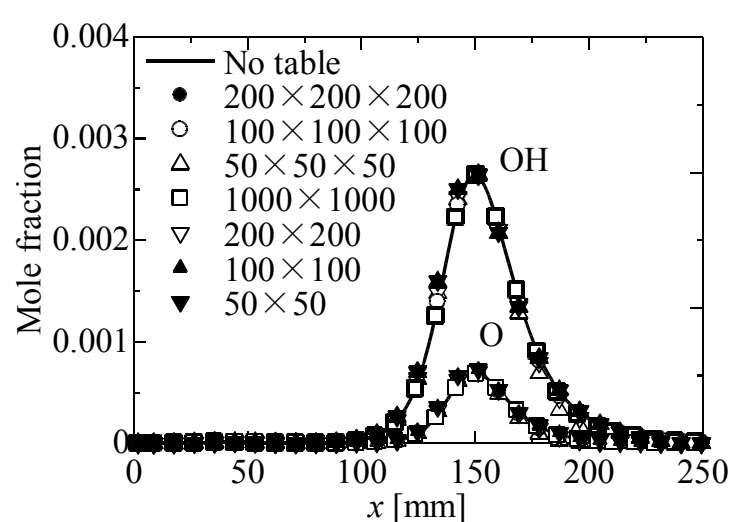

(a)

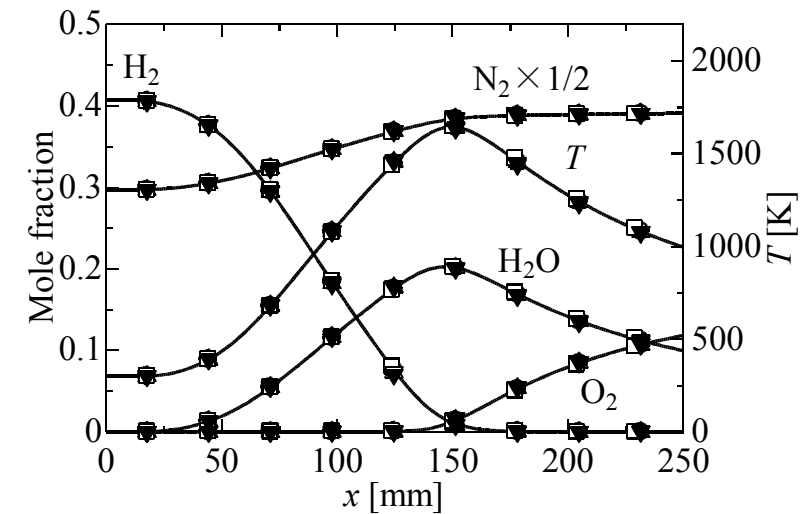

(b)

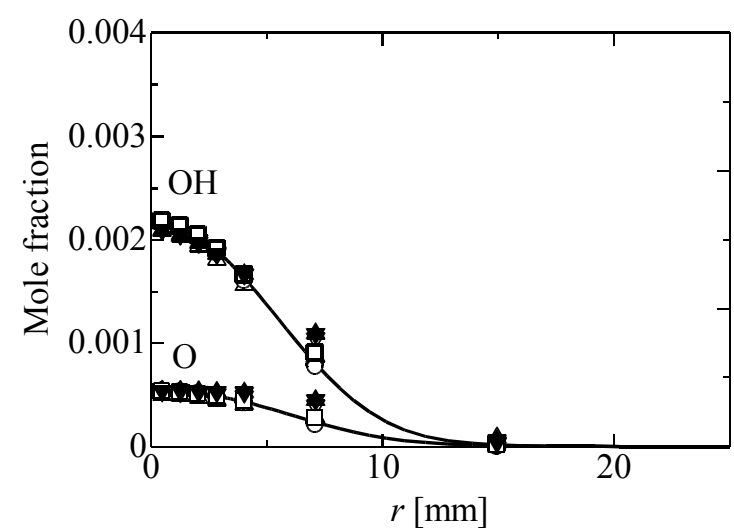

(c)

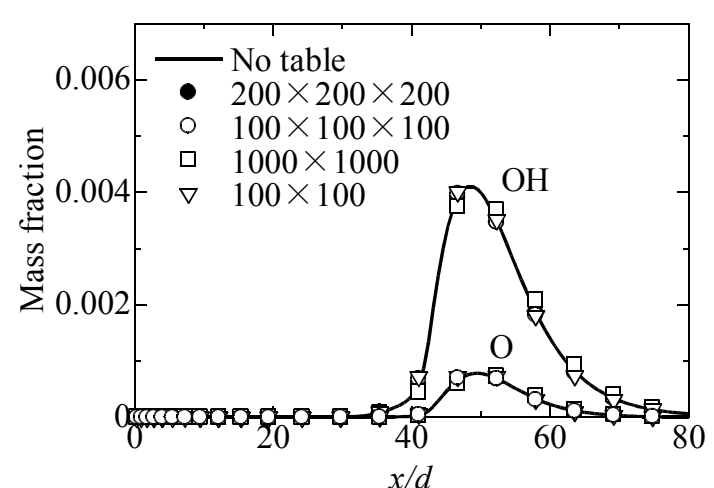

(d)

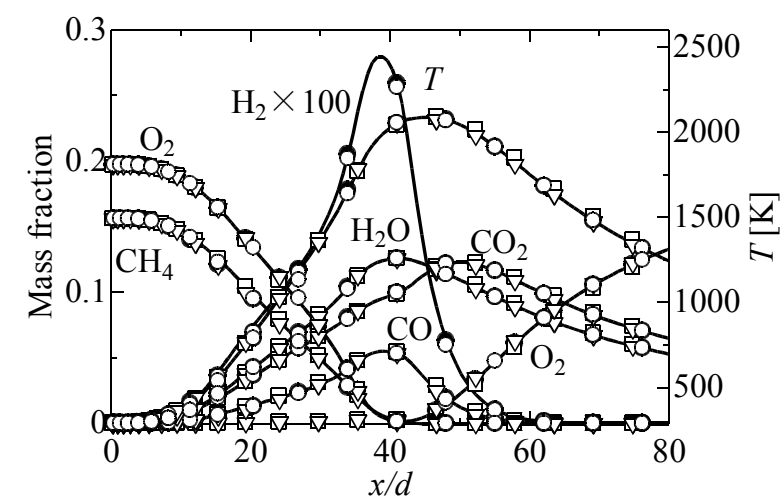

(e)

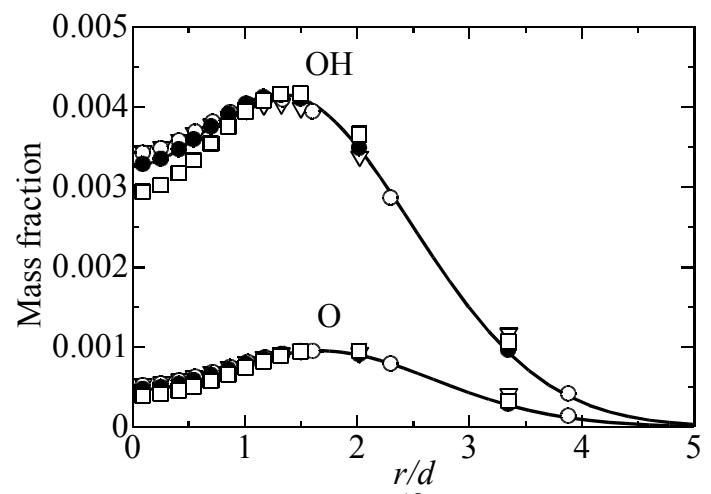

(f)

Fig. 12 Comparison of the results using the look-up table and through direct integration (no look-up table). (a) Axial profiles of the mass fractions of $\mathrm{OH}$ and $\mathrm{O},(\mathrm{b})$ axial profiles of the mass fractions of major species and temperature, and (c) radial profiles of the mass fraction of $\mathrm{OH}$ and $\mathrm{O}$ at $x / d=160$ of the $\mathrm{H}_{2}$-air non-premixed flame. (d) Axial profiles of the mass fractions of $\mathrm{OH}$ and $\mathrm{O}$, (e) axial profiles of the mass fractions of major species and temperature, and (f) radial profiles of the mass fractions of $\mathrm{OH}$ and $\mathrm{O}$ at $x / d=45$ of the $\mathrm{CH}_{4}$-air partially premixed flame.

Figure 11 compares the results of the $\mathrm{CH}_{4}$-air turbulent partially premixed flame obtained through the proposed technique with the experimental data. The computational results were relatively close to the experimental data along the centerline. In contrast, the radial profiles of the computational results were slightly different from the experimental data. For example, the peaks of the $\mathrm{CO}_{2}$ and $\mathrm{H}_{2} \mathrm{O}$ mass fractions and the temperature at $x / d=15$ and 30 did not agree with the experimental data. Similarly, the $\mathrm{O}_{2}$ consumption was overestimated at $x / d=15,30$, and 45 . Thus, the $\mathrm{CO}_{2}$, $\mathrm{H}_{2} \mathrm{O}$, and $\mathrm{O}_{2}$ reaction rates were overestimated in the radial direction. Generally, combustion simulations using an LES model agreed well with the experimental data (Pitsch and Steiner, 2000). To minimize the difference between the predicted results and experimental data, we need to use the LES model. Moreover, the simulation performed using the 
PDF model agreed well with the experimental data (Lindstedt and Ozarovsky, 2005). To improve the computational results, these models should be tested in future work.

\subsection{Comparison with computational data obtained through direct integration and ISAT}

Figure 12 shows the results of the $\mathrm{H}_{2}$ turbulent non-premixed flame and $\mathrm{CH}_{4}$ turbulent partially premixed flame computed through direct integration (no table) and using the look-up table. Several look-up tables $(200 \times 200 \times 200$, $100 \times 100 \times 100,50 \times 50 \times 50,1000 \times 1000,200 \times 200,100 \times 100$, and $50 \times 50$ cells) were tested. The chosen indexes of the look-up table were the mixture fraction, sum of the mass fractions of the product species, and time scale of the reaction. In both cases, the EDC model was chosen as the combustion model. In this section, Kee's mechanism was employed for the $\mathrm{CH}_{4}$ reaction because GRI-Mech 2.11 required extensive computation to estimate the reaction rates without the look-up table.

As shown in Fig. 12 (a) and (b), the results obtained using the look-up table agreed well with those obtained through direct integration. However, in Fig. 12 (c), the results obtained using the two-dimensional look-up table were slightly different from those obtained using direct integration at about $r / d=7.5$.

In Fig. 12 (d) and (e), the results obtained using the look-up table were close to the data obtained through direct integration. The slight difference in the mass fractions of $\mathrm{OH}$ and $\mathrm{O}$ obtained using the two-dimensional look-up table and direct integration was observed at about $r / d=0$ and $r / d=3.5$. Furthermore, the results using the look-up table divided into $50 \times 50 \times 50,100 \times 100$, and $50 \times 50$ cells were omitted because of their poor accuracy. It is noteworthy that the results for $\mathrm{OH}$ and $\mathrm{O}$, which are the radical species, were similar in both cases when using the look-up table divided into $200 \times 200 \times 200$ cells. From the results shown in Fig. 12, we found that three-dimensional look-up table gives better results than that obtained using the two-dimensional look-up table, and a dense look-up table improved the results of the proposed technique.

Figure 13 shows a comparison of the average computational time per iteration of the $\mathrm{CH}_{4}$ partially premixed flame simulation using direct integration (no table), the ISAT method using ANSYS FLUENT, and the proposed technique. The ISAT method was included because the proposed technique is similar to it. The CPU used in these simulations was an Intel Xeon Processor X5680 with 12MB Cache and $3.3 \mathrm{GHz}$ clock speed, and the program was parallelized using 12 threads. GCC 4.5.1 was chosen as the compiler, and CVODE 2.7.0 (Hindmarsh and Serban) was adopted to solve the ODEs of the reaction calculation. As shown in Fig. 14, the computation time required for the proposed technique was a little lower than that required for the ISAT method. The algorithm of the proposed technique is simple yet very efficient.

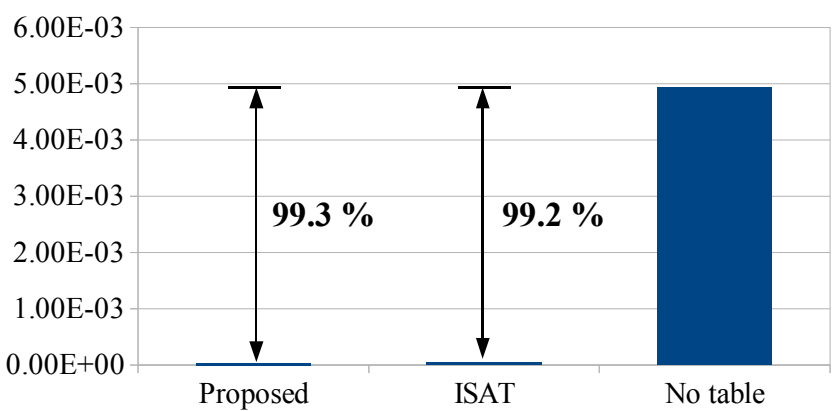

Fig. 13 Computation time per iteration in steady state. (s/iteration, cell)

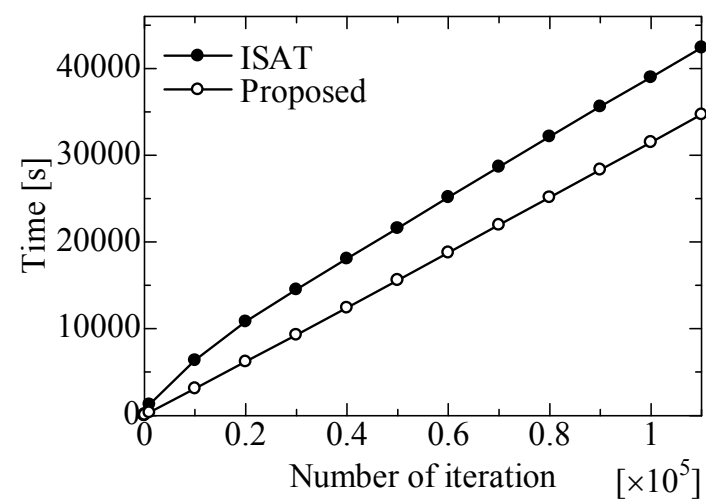

Fig. 14 Comparison of the computation time of the proposed technique with that of the ISAT technique

\section{Conclusion}

In this paper, we have proposed a new simulation technique based on a look-up table, in which the look-up table is constructed during the simulation. In the proposed technique, the reaction rates are obtained from the look-up table if data are available. However, if the data are not available, the reaction equation is directly integrated, and the obtained 
reaction rates are stored in the look-up table according to the indexes. The proposed technique was applied to the EDC model. Furthermore, a $\mathrm{H}_{2}$ turbulent non-premixed flame and $\mathrm{CH}_{4}$ turbulent partially premixed flame were simulated, and the computational results were validated by comparing the $\mathrm{H}_{2}$ turbulent non-premixed flame (Takagi and Kotoh, 1982) and $\mathrm{CH}_{4}$ turbulent partially premixed flame (TNF Workshop).

The results of the $\mathrm{H}_{2}$ turbulent non-premixed flame simulation obtained through the proposed technique agreed with the experimental data, and the computational results of the $\mathrm{CH}_{4}$ turbulent partially premixed flame were close to the experimental data along the centerline. In contrast, the radial profiles of the computational results were slightly different from the experimental data. Furthermore, the results obtained through the proposed technique using the look-up table divided into $200 \times 200 \times 200$ cells agreed well with those obtained using the EDC model without the look-up table. Therefore, we draw following conclusions:

- The approach using the combination of the Reynolds stress model, EDC, and look-up table showed relatively good agreement with the experimental data. However, the LES model and other recent combustion models should be tested for further improvement of the simulation.

- A coarse look-up table causes differences in the results between the proposed technique and direct integration; the look-up table divided into $200 \times 200 \times 200$ was sufficient for good results.

- The proposed technique reduced the computation time by $99 \%$ compared with the direct integration technique.

- Although the algorithm of the proposed technique is simple, our method is very efficient.

\section{References}

ANSYS, Inc., FLUENT Theory Guide 13 (2010), pp. 48-95, ANSYS, Inc.

Baba, Y. and Kurose, Y., Analysis and flamelet modeling for spray combustion, Journal of Fluid Mechanics, Vol. 612, No. 1 (2008), pp. 45-79.

Barlow, R. S. and Smith, N. S., Nitric oxide formation in dilute hydrogen jet flames: Isolation of the effects of radiation and turbulence-chemistry submodels, Combustion and Flame, Vol. 117 (1999), pp. 4-31.

Bilger, R. W., Turbulent Reacting Flow (1980), pp. 65-113, Springer-Verlag.

Bowman, C. T., Hanson, R.K., et al., GRI-Mech 2.11, < http://diesel.me.berkeley.edu/ gri_mech/new21/> (accessed on 201306 13).

Carbonell, D., Perez-Segarra, C. D., Coelho, P. J. and Oliva, A., Flamelet mathematical models for non-premixed laminar combustion, Combustion and Flame, Vol. 156, No. 2 (2009), 334-347.

Fiorina, B., Vicquelin, R., Auzillon, P., Darabiha, N., Gicquel, O. and Veynante, D., A filtered tabulated chemistry model for LES of premixed combustion, Combustion and Flame, Vol. 157 (2010), pp. 465-475.

Fox, O. R., Computational models for turbulent reacting flows (Kindle edition), (2003), Chapter 6, Cambridge University Press.

Fukumoto, K. and Ogami, Y., Turbulent diffusion combustion model using chemical equilibrium combined with the eddy dissipation concept for reducing detailed chemical mechanisms: An application of $\mathrm{H}_{2}$-air turbulent diffusion flame, Heat Transfer-Asian Research, Vol. 39, No. 5 (2010), pp. 292-313.

Fukumoto, K. and Ogami, Y., Combustion simulation technique for reducing chemical mechanisms using look-up table of chemical equilibrium calculations: Application to $\mathrm{CO}-\mathrm{H}_{2}-$ Air turbulent non-premixed flame, Computers \& Fluids, Vol. 66, No. 15 (2012), pp. 98-106.

Fukumoto, K. and Ogami, Y., Simulation of CO- $\mathrm{H}_{2}$-air turbulent nonpremixed flame using the eddy dissipation concept model with lookup table approach, Journal of Combustion, Vol. 2012, No. 496460 (2012a).

Fukumoto, K. and Ogami, Y., Simulation of $\mathrm{CH}_{4}-\mathrm{H}_{2}$-air turbulent diffusion flame using look-up table approach, The Eighth KSME-JSME Thermal and Fluid Engineering Conference, No. FR10-007 (2012b).

Gicquel, O., Darabiha, N. and Thevenin, D., Laminar premixed hydrogen/air counterflow flame simulations using flame prolongation of ILDM with differential diffusion, Proceedings of the Combustion Institute, Vol. 28, No. 2 (2000), pp. 1901-1908.

Godel, G., Domingo, P. and Vervisch, L., Tabulation of $\mathrm{NO}_{\mathrm{X}}$ chemistry for large-eddy simulation of non-premixed turbulent flames, Proceedings of the Combustion Institute, Vol. 32, No. 1 (2009), pp. 1555-1561.

Gran, I. R. and Magnussen, B. F., A Numerical study of a bluff-body stabilized diffusion flame. Part 1. Influence of turbulence modeling and boundary conditions, Combustion Science Technology, Vol. 119, No. 1-6 (1996a), pp. 
171-190.

Gran, I. R. and Magnussen B. F., A numerical study of a bluff-body stabilized diffusion flame. Part 2. Influence of combustion modeling and finite-rate chemistry, Combustion Science Technology, Vol. 119, No. 1-6 (1996b), pp. 191-217.

Hindmarsh, A. C. and Serban, R., CVODE version 2.7.0. <https://computation.llnl.gov/casc/sundials/main.html $>$ (accessed on 201306 13).

Ihme, M., Cha, C. M. and Pitsch, H., Prediction of local extinction and re-ignition effects in non-premixed turbulent combustion using a flamelet/progress variable approach, Proceedings of the Combustion Institute, Vol. 30, No. 1 (2005), pp. 793-800.

Kee, R. J., Grcar, J. F., Smooke, M. D. and Miller, J. A., A program for modeling steady, laminar, one-dimensional premixed Flames, SAND 85-8240 (1985).

Lindstedt, R. P. and Ozarovsky, H. C., Joint scalar transported PDF modeling of nonpiloted turbulent diffusion flames, Combustion and flame, Vol. 143, No. 4 (2005), pp. 471-490.

Maas, U. and Pope, S. B., Simplifying chemical kinetics: Intrinsic low-dimensional manifolds in composition space, Combustion and Flame, Vol. 88, No. 3 (1992), pp. 239-264.

Maas, U. and Pope, S. B., Laminar flame calculations using simplified chemical kinetics based on intrinsic low-dimensional manifolds, Twenty-fifth symposium on combustion, Vol. 25, No. 1 (1994), pp. 1349-1356.

Magnussen, B. F., On the structure of turbulence and a generalized eddy dissipation concept for chemical reaction in turbulent flow, 19th AIAA Aerospace Meeting (1981).

Magnussen, B. F., Modeling of $\mathrm{NO}_{\mathrm{X}}$ and soot formation by the eddy dissipation concept, 1st Topic Oriented Technical Meeting (1989).

Magnussen, B. F., The eddy dissipation concept: A bridge between science and technology, ECCOMAS Thematic Conference on Computational Combustion (2005).

Moriai, H., Kurose, R. et al., Large-eddy simulation of turbulent spray combustion in a subscale aircraft jet engine combustor-Predictions of NO and soot concentrations, Journal of Engineering for Gas Turbines and Power, Vol. 135, No. 9 (2013).

Moureau, V., Domingo, P. and Vervisch, L., From large-eddy simulation to direct numerical simulation of a lean premixed swirl flame: Filtered laminar flame-PDF modeling, Combustion and Flame, Vol. 158, No. 7 (2011), pp. 1340-1357.

Ogami, Y. and Fukumoto, K., Simulation of combustion by vortex method, Computers \& Fluids, Vol. 39 (2010), pp. 592-603.

Oijen, J. A. V., Lammers, F. A. and Goey, L. P. H. de., Modeling of complex premixed burner system by using flamelet-generated manifolds, Combustion and Flame, Vol. 127, No. 3 (2001), pp. 2124-2134.

Patankar, S. V., Numerical heat transfer and fluid flow Japanese edition., Morikita Publishing Co., Ltd, 1985.

Peng, L. and Jian, Z., Simulation of turbulent combustion and NO formation in a swirl combustor, Chemical Engineering Science, Vol. 64, No. 12 (2009), pp. 2903-2914.

Peters, N., Laminar diffusion flamelet models in non-premixed turbulent combustion, Progress in Energy and Combustion Science, Vol. 10. No. 3 (1984), pp. 319-339.

Pierce, C. D. and Moin, P., Progress-variable approach for large-eddy simulation of non-premixed turbulent combustion, Journal Fluid Mechanics, Vol. 504, No. 1 (2004), pp. 73-97.

Pitsch, H. and Steiner, H., Large eddy simulation of a turbulent piloted methane/air diffusion flame (Sandia flame D), Physics of Fluids, Vol. 12, No. 10 (2000), pp. 2541-2554.

Pope, S. B., Computationally efficient implementation of combustion chemistry using in situ adaptive tabulation, Combustion Theory and Modeling, Vol. 1 (1997), pp. 41-63.

Sadiki, A., Maltsev, A., Wegner, B., Flemming, F., Kempf, A. and Janicka, J., Unsteady methods (URANS and LES) for simulation of combustion systems, International Journal of Thermal Sciences, Vol. 45, No. 8 (2006), pp. $760-773$.

Singer, M. A. and Pope, S. B., Modeling unsteady reacting flow with operator splitting and ISAT, Combustion and Flame, Vol. 147, No. 1 (2006), pp. 150-162.

Smooke, M. D., Reduced kinetic mechanisms and asymptotic approximations for methane-air flame: A Topical Volume, Lecture Notes in Physics (1991), Springer-Verlag.

Takagi, T. and Kotoh, S., Prediction of flow and combustion in turbulent diffusion flames, Transactions of the Japan 
Society of Mechanical Engineers series B, Vol. 48, No. 436 (1982), pp. 2609-2617, (in Japanese)

TNF Workshop. "Sandia/TUD Piloted $\mathrm{CH}_{4} /$ Air Jet Flames" (online), available from <http://www.sandia.gov/TNF/>, (accessed on 201306 13).

Wang, H. and Pope, S. B., Large eddy simulation/probability density function modeling of a turbulent $\mathrm{CH}_{4} / \mathrm{H}_{2} / \mathrm{N}_{2}$ jet flame, Proceedings of the Combustion Institute, Vol. 33, No. 1 (2011), pp. 1310-1330.

Yang, B. and Pope, S. B., Treating chemistry in combustion with detailed mechanisms-in situ adaptive tabulation in principal directions-premixed combustion, Combustion and Flame, Vol. 112, No. 1 (1998), pp. 85-112.

Zhou, X., Sun, Z. Brenner, G. and Durst, F., Combustion modeling of turbulent Jet diffusion $\mathrm{H}_{2} /$ air Flame with detailed chemistry, International Journal of Heat and Mass Transfer, Vol. 43 (2000), pp. 2075-2088. 